\title{
Himalayan Dreams-Travel Blogs as Cultural Constructs in Post -Truth Era
}

\section{Reethi P}

Research Scholar in English

St. Xavier's College for Women

Aluva, Kerala, India

reethi_p@rediffmail.com

Dr. Milon Franz

Research Scholar in English

St. Xavier's College for Women

Aluva, Kerala, India

\section{Abstract}

Travel blogs can be considered as alternative literature. Travel blogs are the digitised version of travelogues or travel narratives. The blogs give impressive, cost effective and immediate impressions of travel. Earlier, the traveller prepares notes during the travel and writes it after reaching his native place. It involves revisualising the entire trip and jotting down the entire memories. The narration adds the real and the images he visualized. The narration will be a mix of myths and personal perspectives. The blogs are live reports of the travel. The rationale of the study understands the digital space and the awareness of "truth". In the post truth era frontiers are blurred between truth and lie, honesty and dishonesty, fiction and non fiction. Keywords: Travel Blogs, Culture, Post Truth and Himalayan Travelogues 
Travel blogs are forms of digital story telling or diary writing which manifest the travel experiences of travellers. Travel blogs are an inexpensive means to gather authentic feedback and information related with travel. Blog is the short form of Weblog and it was initiated in 1998. Blogging includes entertainment, information, social interaction and selfexpression. Blogs offer the opportunity to reveal tourist's interpretations of his experiences, and to express tourist's impressions, perceptions, thoughts, and feelings. Travel blog is an individual entry by tourist as a report to his /her family and friends. Technology is the modern medium, where life is chronicled recently.

Travel blog can be considered as alternative literature. Betsy A. Pudiner(2008) initiates the examination and discussion of the cultural and promotional power of weblogs and blogging. Robinson and Anderson(2002:6) pose that travel writing 'can legitimately be analysed to see how they reflect and shape the economic, political and social realities of the world. 'Research by Bing Pan, Tanya MacLaurin and John C. Crotts(2007), has shown that interpersonal influence arising from opinion exchange between consumers is an important factor influencing consumer's purchase decisions. The popularity of travel blog sites such asTravelBlog.org and Travel Post.com, facilitate powerful discussion that could affect consumer decisions and destination images says the research by Wegnger (2008). Maria Banyai and Troy D. Glover (2014)studies about the increase of online diaries or blogs, and the effects on communication channel and also the way tourism destinations are being promoted and consumed.

In these studies the travel blogs are considered as strategy to sell the product -travel. The gap identified and analyzed is about the blogs as cultural representations in a post truth era. Here the commoditized product is considered as a cultural representation, which reflects the new pseudo real world of virtual. The paper analyses Himalayan dreams- a travel blog which sketches Himalayan Ranges as destination. Himalayan dreams is a travel blog sharing 
experiences and dreams which claims it as "a collection of inspiring travel stories and experiences and writing, photo essays, cultural history, favourite experiences, festivals, food, culture and adventure.” They organize holidays in Nepal, Bhutan, Tibet and India. Many travel blogs are intended to sell the product, so they create opinions. It scripts about vivid experiences in the Himalayan Valley.

The digital version of travel narratives- the blogs give impressive, cost effective and immediate impressions of travel. Earlier, the traveller prepares notes during the travel and writes it after reaching his native place. The author revisualises the entire trip and writes down the entire memories. The narration adds the real and the images he visualized. The narration will be a mix of facts and fiction, it includes myths and subjective attributions of the writer. The blogs are live reports of the travel. The rationale of the study understands the digital space and the awareness of "truth". Truth is the accordance with fact or reality. The question this paper raises is whether blogs are truth or post truth. The spaces shared by blogs are virtual spaces. The concept of truth has been questioned by great philosophers, and now the world is going through a period of post truth- a concept where truth does not exist. So, Can the virtual space be real?

Post Truth is defined in Oxford Dictionary as denoting or relating to circumstances whereby objective facts are less influential in shaping the opinion of the public than appeals to personal belief and emotion. The post truth era is characterized by lies, propaganda and fake news. The post truth is a postmodern concept which closely associates with Baudrillard's simulacrum. Now days we have truth, lies, and some statements that might be false, which are "the truth improved". In the post truth era frontiers are blurred between truth and lie, honesty and dishonesty, fiction and non fiction.

Globalisation and the World Wide Web raised the acquaintances with strangers in the virtual world, for eg. Facebook, Twitter etc. Post truthfulness and cultural carelessness build 
a fragile social edifice based on suspicion, eroding the foundation of trust that underlies any healthy civilization. The notion of simulacrum is a product of deception, often for gain. The same strategy is used in blog where to sell the tourism products. Post truth amounts to a form of ideological supremacy, which tries to compel someone to believe in something whether there is good evidence for it or not. Consciousness is pure awareness, governed by truth. To have an unaltered consciousness, the mind must be silent. When the mind is silent, beingness commences and we can see truth. There is no single truth, as the world exists in plural. Arendt writes:

There always comes the point beyond which lying becomes counter-productive. This point is reached when the audience to which the lies are addressed is forced to disregard altogether the distinguishing line between truth and falsehood in order to be able to survive. Truth or falsehood- it does not matter which anymore, if your life depends on your acting as though you trusted; truth that can be relied on disappears entirely from public life, and with it the chief stabilizing factor in the ever- changing affairs of men

Post truth theory puts forward that the public opinion is shaped not by objective facts but appeals to emotional and personal belief. Travel blogs also use the same technique to influence the readers. The virtual blog readers are following the suggestions, appeals and personal beliefs of the blogger. The directions and suggestions provided by the blogger influences the reader and influence his/ her decision in fixing the trip.

A blog covers overall aspect of a visit from anticipation to the actual experience at the destination and from attractions to amenities to the overall impression. The traveler collects data and bloggers represent a particular sub group. Blogger reflects what he has seen added with the colours of imagination. These truths are subjective truths; another traveller may not 
visualize the same in the same place. For instance, the blog Namtso Lake: Tibet's Celestial Waters says about Namsto Lake as:

Each morning, suspended over Namtsolake, one can watch the sun and the sky plat their wistful early rays upon the sparkly blue waters and transform it into various shades and hues. Within a few moments, the water glows. Bathed in, lazy beams of the early sun, the shimmering lake reflects back a bright radiance that makes the atmosphere hum with vibrant animated awakening. Namsto Lake is heavenly, which is also what the name means in Tibetan language.

The quote suggests that Namsto Lake is heavenly, but what is real heaven? The concept of heaven is not real; it is a concept that exists within post truth ideology. So how can a traveller decide the heaven another person has experienced? The Himalayan ranges do not have stable weather condition. A traveller visiting the place with these images and imaginations may feel cheated if he is not able to experience the same. The concept of truth is thus getting deconstructed in this era of post truth. Ram Chhetri in his blog Into thin Air-Pathway to Heaven says:

The wind, outside, suddenly stopped as if someone had hit a switch and all fell silent. Mt. AmaDablam removed her veil of clouds and flashed an expansive smile of pure snow, rock and ice. Mt. Everest, with its symmetrical shape was mesmerizing. The whole new vista opened up, causing me to scream or in the excitement lose my dinner. I was without a thought and completely speechless for the longest time. These are some of the unique experiences of the traveller which is explained or narrated in the virtual communities, as people engage in wide variety of activities online these days. Blog space creates virtual relationships and communities, creating a new type of reality through search engines in the online space. 
The geographic details of the place, weather conditions, conveyance, cost effective food and stay are discussed in detail. Himalaya is a place where climate changes regularly, these variations and details of precautions taken are discussed in the blogs. The photos and videos enhance the visual representations. It shows the life of people, their food and how the life is different from the native place of the blogger. The narrative elaborates the myth associated and information (historical facts) gathered by the blogger. But these are presented subjectively and there are chances of ignoring objective facts. This rejection of selected truth is a feature of post truth era. Thus the travel blogs become cultural constructs of propaganda. Of course, rationally we can make our own judgments but the unconscious will be influenced by the virtual world and it reflects in society and moulds a culture which will be considered as an offspring of Post truth era. 


\section{Works Cited}

Arendt, Hannah. Crises of the Republic; Lying in Politics, Civil disobedience on Violence, Thoughts on Politics, and Revolution.ISBN 0151230951.

Chetri, Ram.'Into Thin Air- Pathway to Heaven.” Himalayan Dreams, 21 June 2019, http:Himalayan dreams.org.

Pudiner, Betsy A.”Alternative Literature and Tourist Experience: Travel and Tourist Weblogs."Journal of Tourism and Cultural Change, Routledge 29 December 2014.http://dx.doi.org/10.2167/jtcc051.0

Pan, Bing. Tanya MacLAurin and John C. Crotts."Travel Blogs and the Implications for Destination Marketing."Journal of Travel Research, 46(1),35-45.2007 Doi: $10.1177 / 0047287507302378$

Banyai, M.and Glover T.D. "Evaluating Research Methods on Travel Blogs.”Journal of Travel Research, 51(3), 267-277.2011.doi:10.1177/0047287511410323.

Mambrol, Nasrullah. Post- Truth.Literariness.org.2018.

McIntyre, Lee. Post-Truth. Cambridge, 2018 